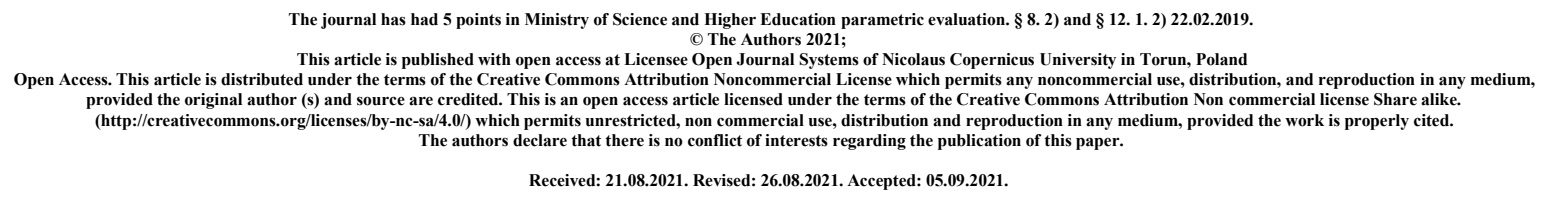

\title{
Postcovid pulmonary complication
}

\section{${ }^{1}$ Tomasz Korzec, ${ }^{1}$ Maria Kalicka, ${ }^{1}$ Przemysław Raczkiewicz, ${ }^{1}$ Konrad Kania, ${ }^{2}$ Katarzyna Cyboran}

\author{
${ }^{1}$ Medical University of Lublin, Faculty of Medicine, Lublin, Poland \\ ${ }^{2}$ Medical Faculty, Institute of Medical Sciences, Collegium Medicum, Opole, Poland
}

\begin{abstract}
Abstrakt
Introduction:

The World Health Organization in March 2020 announced a pandemic of COVID-19 disease caused by the SARS-CoV-2 virus. It is one of the seven species known to be pathogenic to humans in this group of viruses. The incubation period of the virus is 2-14 days, usually about 5 days. SARS-CoV-2 uses the ACE2 receptor to enter the host's mucosa and cause an active infection. Symptomatic infection may be complicated by reversible or irreversible changes in the lungs and pulmonary embolism.
\end{abstract}

\section{Method:}

Recent literature was reviewed based on PubMEd, Google scholar, using words: covid lung, post covid lung, post covid, covid lung fibrosis,

\section{Objective:}

Systematisation of information on pulmonary postovid complications

Key words: lung post covid, covid lung 


\section{Introduction:}

The World Health Organization in March 2020 announced a pandemic of COVID-19 disease caused by the SARS-CoV-2 virus. It is one of the seven species known to be pathogenic to humans in this group of viruses. During the SARS -Cov2 virus pandemic, people are the reservoir of infection. The virus is transmitted by airborne droplets, the infectious material is secreted from the respiratory tract. [1] The incubation period of the virus is 2-14 days, usually about 5 days. Infection may be symptomatic or not. Possible symptoms are:

- symptomatic infection without pneumonia - cough, sore throat, rhinitis, malaise, headache, muscle pain, diarrhea, conjunctivitis, changes in smell and taste

- mild pneumonia

- severe pneumonia with tachypnoe $>30 / \mathrm{min}$ lub $\mathrm{SpO} 2<90 \%$

- ARDS

- Sepsis and septic shock [2]

Based on the time criteria adopted by the British NICE agency (National institute for Health and Care Excelence), the following course of COVID-19 is distinguished:

- acute COVID-19 - symptoms of infection lasting up to 4 weeks,

- persistent symptomatic COVID-19 - symptoms lasting for 4 to 12 weeks,

- post-COVID-19 syndrome - symptoms that developed during or after the infection, consistent with those of COVID-19, lasting more than 12 weeks for which there is no other explanation [2]

The affinity of coronaviruses, including the SARS-CoV-2 virus, for the respiratory epithelium is due to the fact that the angiotensin converting enzyme 2 (ACE2) recpetor is one of the potential targets for SARS-CoV-2 in the human body. The ACE2 receptor is expressed in a variety of tissues, including the upper and lower respiratory tract. SARS-CoV-2 uses the ACE2 receptor to enter the host's mucosa and cause an active infection. [3] Other places in the human body, ACE2 tests, gastrointestinal tract, vessels, brain, liver, kidneys, spleen, skin. This can lead to possible short term and long term complications from other organs. However, the main target of the SARS-CoV-2 virus and the cause of the highest percentage of hospitalizations of patients are the respiratory tract, which we will focus on later in this article.

\section{Stay of knowledge:}

Pathological changes in the respiratory system are caused by the reaction of the immune system to the infection. With the help of S proteins and recalled ACE2 receptors, the 
virus enters the cells of the lower respiratory tract and causes increased damage to the alveoli with damage to the alveolar-capillary barriery, the connection through which the exchange of oxygen and carbon dioxide between the alveoli and capillaries. In addition, there is an accumulation of neutrophils - the cells of the immune system in the vesicles, which cause an inflammatory reaction in them with the formation of exudate. The whole process involves not only the aforementioned neutrophils, but also pro-inflammatory cytokines and complement components, which are elements of the immune system. They attack cells infected by the virus and stimulate the body to fight infection. One of the main mechanisms of the development of acute respiratory distress syndrome is the uncontrolled systemic inflammatory reaction resulting from the release of large amounts of pro-inflammatory cytokines and chemokines by immune cells in response to virus antigens - the phenomenon of cytokine storm $[5,6]$. In this article, we will try to answer the question of how the inflammatory process in the pulmonary parenchyma in the course of covid 19 disease affects the image of the lungs in imaging tests and the functionality of the lungs.

There is no single characteristic picture of changes in the lung imaging tests, which we could clearly say that we are dealing with viral pneumonia in the course of Covid19. We will not see any changes in most patients who are asymptomatically infected. In other patients, the lesions of the disease may completely reverse and the lungs will be completely normal, as before the disease. In some patients, after undergoing covid 19, the picture of interstitial pneumonia remains with lesions located bilaterally, peripherally, most often in the lower parts of the lungs. The changes may take the form of shading of the opal glass type, consolidation, multifocal changes and linear shading. In most patients with postcovid changes in the lungs, the changes disappear with time, but in some patients they become fibrotic, disturbing the architecture of the surrounding parenchyma, which translates into a deterioration of the gas 


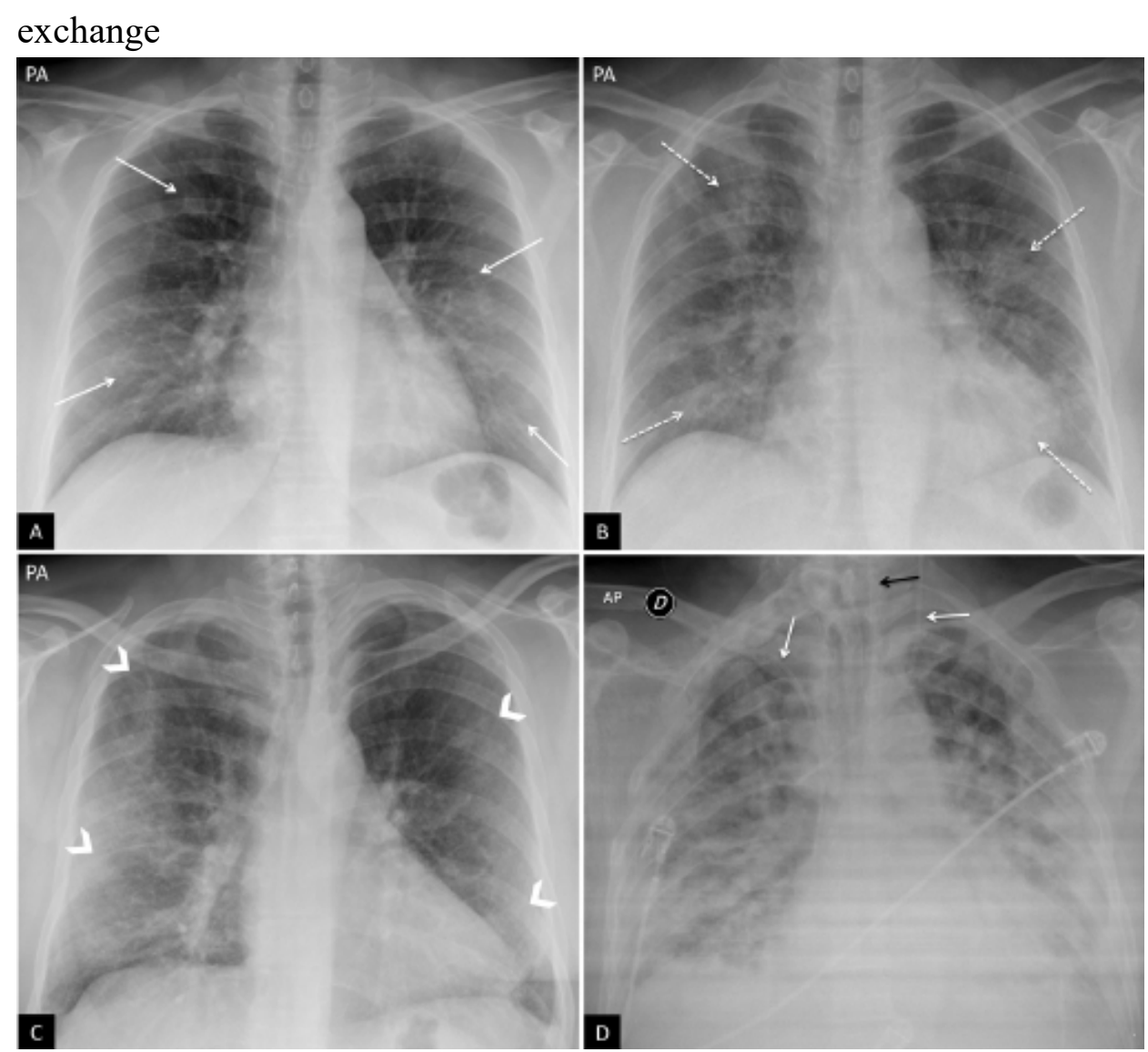

efficiency.[7].

Figure 1. [8] Images of the chest in the PA projection in patients with confirmed covid 19 by PCR.

Typical findings in COVID-19 pneumonia. (A) A 47-year-old woman with signs and symptoms raising suspicion of COVID-19. Posteroanterior (PA) chest X-ray. Reticular interstitial pattern with peripheral predominance (arrows). (B) Same patient as in image A. PA chest X-ray taken 3 days later. Positive PCR for SARS-CoV-2. Despite being taken with poorer inspiration, the X-ray shows faint rounded bilateral peripheral alveolar opacities (dotted arrows). (C) A 57-year-old male with dyspnoea and positive PCR for SARS-CoV-2. Bilateral peripheral opacities in upper, middle and lower fields (arrow tips). (D) A 45-year-old male with dyspnoea and COVID-19 confirmed by PCR. Anteroposterior chest X-ray showing multiple bilateral diffuse confluent areas of consolidation with extensive involvement of both lungs. Note the presence of two central venous lines, one left jugular and the other right subclavian (white arrows), and a gastrointestinal tube (black arrow).

\section{Discussion:}

In most patients, these lesions can reverse by a repair process that involves regeneration of damaged tissue by dividing stem cells and depositing connective tissue to fill areas of damaged pulmonary parenchyma. The most important role in this process is played by macrophages, which phagocytose damaged fragments of alveoli and produce essential substances such as cytokines and growth factors responsible for the repair of lung tissue.. 
Factors released by macrophages stimulate angiogenesis and activation of fibroblasts that accumulate collagen.

The situation is different if there are exudates in the alveoli. It is a characteristic phenomenon of acute respiratory distress syndrome (acute respiratory distress syndrome, ARDS), which also known as "wet lung". In this case, the fibroblasts involved in the repair process are transformed into myofibroblasts, which results in a change in the architecture and organization of the pulmonary parenchyma. The repair process includes factors such as epidermal growth factor (EGF), transforming growth factor alpha (TGF-a), vascular endothelial growth factor (VEGF), and fibroblast growth factor (FGF). There is a proliferation of bronchiolar stem cells and their replacement of the diseased alveolar epithelium, angiogenesis of pulmonary capillaries. The simultaneous processes of fibrinolysis, reconstruction of interstitial tissue, proliferation of epithelium and endothelium in the case of undamaged basal membranes of alveolar epithelium make repair still possible. On the other hand, when the damage to the lungs is large, as is the case in ARDS, the basal membranes are also damaged. Then, among all repair processes, fibroblastic processes gain the upper hand. Damaged cells are replaced with stiff scar tissue. Its accumulation causes pulmonary fibrosis - a condition that leads to a deterioration in lung function and exercise capacity. It is the more likely the more severe the COVID-19 infection is [9,10]. Patients hospitalized due to the severe course of COVID-19 receive prophylactic anticoagulants due to the greater probability of venous disease thromboembolism. The most common form of thromboembolism in this group of patients is pulmonary embolism. Embolism occurs as a result of a narrowing or occlusion of the pulmonary artery by the embolic material, which usually comes from the deep veins of the lower limbs. Gas exchange is impaired, and often also heart failure. It is a state of imminent threat to life. Due to the fact that symptoms of pulmonary embolism manifestation are similar to those of covid, diagnosis is difficult [11] Post-mortem studies show that impaired blood flow can also lead to the formation of local thrombosis, which may be caused by immunological and inflammatory factors. [12]

\section{Conclusions:}

In some cases, COVID-19 infection leaves an image of interstitial pneumonia, the lesions may take the form of milk-glass shading, consolidation, multifocal lesions and linear shadows. In most patients, these changes regress with time, but in some patients they become fibrotic, disturbing the architecture of the surrounding parenchyma, which translates into a deterioration of the gas exchange efficiency. Another serious pulmonary complication of COVID-19 is pulmonary embolism, primarily caused by blood clots originating in the lower limbs.

Bibliography:

1. Zhu N, Zhang D, Wang W, Li X, Yang B, Song J, Zhao X, Huang B, Shi W, Lu R, Niu P, Zhan F, Ma X, Wang D, Xu W, Wu G, Gao GF, Tan W; China Novel Coronavirus Investigating and Research Team. A Novel Coronavirus from Patients with Pneumonia in China, 2019. N Engl J Med. 2020 Feb 20;382(8):727-733. doi: 10.1056/NEJMoa2001017. Epub 2020 Jan 24. PMID: 31978945; PMCID: PMC7092803. 
2. Interna Szczeklika. Mały podręcznik 2020/21. / [red.prow.] Piotr Gajewski, Wyd.12, Kraków : Wydawnictwo Medycyna Praktyczna, 2020

3.National Institute for Health and Care Excellence. COVID-19 rapid guideline: managing the long-term effects of COVID-19. https://www.nice.org.uk/guidance/ng188

4. Li YC, Bai WZ, Hashikawa T. The neuroinvasive potential of SARS-CoV2 may play a role in the respiratory failure of COVID-19 patients. J Med Virol. 2020 Jun;92(6):552-555. doi: 10.1002/jmv.25728. Epub 2020 Mar 11. PMID: 32104915 ; PMCID: PMC7228394.

5. Hu, B., Huang, S., \& Yin, L. (2020). The cytokine storm and COVID-19. Journal of Medical Virology. doi:10.1002/jmv.26232

6 Elżbieta Nowakowska, Sylwia Sulimiera Michalak, COVID-19 - CHOROBA WYWOŁANA ZAKAŻENIEM WIRUSEM SARS-COV-2 GLOBALNYM ZAGROŻENIEM DLA ZDROWIA PUBLICZNEGO, POSTĘPY MIKROBIOLOGII ADVANCEMENTS OF MICROBIOLOGY 2020, 59, 3, 227-236 DOI: 10.21307/PM2020.59.3.16

7. Ng MY, Lee EYP, Yang J, Yang F, Li X, Wang H, Lui MM, Lo CS, Leung B, Khong PL, Hui CK, Yuen KY, Kuo MD. Imaging Profile of the COVID-19 Infection: Radiologic Findings and Literature Review. Radiol Cardiothorac Imaging. 2020 Feb 13;2(1):e200034. doi: 10.1148/ryct.2020200034. PMID: 33778547; PMCID: PMC7233595.

8. Martínez Chamorro E, Díez Tascón A, Ibáñez Sanz L, Ossaba Vélez S, Borruel Nacenta S. Radiologic diagnosis of patients with COVID-19. Diagnóstico radiológico del paciente con COVID-19. Radiologia (Engl Ed). 2021;63(1):56-73. doi:10.1016/j.rx.2020.11.001

9. Ojo AS, Balogun SA, Williams OT, Ojo OS. Pulmonary Fibrosis in COVID-19 Survivors: Predictive Factors and Risk Reduction Strategies. Pulm Med. 2020 Aug 10;2020:6175964. doi: 10.1155/2020/6175964. PMID: 32850151; PMCID: PMC7439160.

10. Zuo W, Zhao X, Chen YG. SARS Coronavirus and Lung Fibrosis. Molecular Biology of the SARS-Coronavirus. 2009;247-258. Published 2009 Jul 22. doi:10.1007/978-3-64203683-5_15

11. Oissy J, Goutay J, Caplan M, Parmentier E, Duburcq T, Lassalle F, Jeanpierre E, Rauch A, Labreuche J, Susen S, Lille OIOM Hemostaza COVID-19 Group (2020) Zatorowość płucna u pacjentów z COVID-19: świadomość zwiększona częstość występowania. obieg 142:184-186

12. Carsana L, Sonzogni A, Nasr A, Rossi RS, Pellegrinelli A, Zerbi P, Rech R, Colombo R, Antinori S, Corbellino M, Galli M, Catena E, Tosoni A, Gianatti A, Nebuloni M. Pulmonary post-mortem findings in a series of COVID-19 cases from northern Italy: a two-centre descriptive study. Lancet Infect Dis. 2020 Oct;20(10):1135-1140. doi: 10.1016/S14733099(20)30434-5. Epub 2020 Jun 8. PMID: 32526193; PMCID: PMC7279758. 